\title{
BMJ Open Challenges, experience and coping of health professionals in delivering healthcare in an urban slum in India during the first 40 days of COVID-19 crisis: a mixed method study
}

\author{
Carolin Elizabeth George,${ }^{1}$ Leeberk Raja Inbaraj (10 , ${ }^{1}$ Shon Rajukutty, ${ }^{1}$ \\ Luc P de Witte ${ }^{2}$
}

To cite: George CE, Inbaraj LR, Rajukutty S, et al. Challenges, experience and coping of health professionals in delivering healthcare in an urban slum in India during the first 40 days of COVID-19 crisis: a mixed method study. BMJ Open 2020;10:e042171. doi:10.1136/ bmjopen-2020-042171

- Prepublication history and additional material for this paper are available online. To view these files, please visit the journal online (http://dx.doi. org/10.1136/bmjopen-2020042171).

Received 29 June 2020 Revised 27 0ctober 2020 Accepted 29 0ctober 2020

Check for updates

(c) Author(s) (or their employer(s)) 2020. Re-use permitted under CC BY-NC. No commercial re-use. See rights and permissions. Published by BMJ.

${ }^{1}$ Department of Community Health \& Family Medicine, Bangalore Baptist Hospital, Bangalore, Karnataka, India ${ }^{2}$ Centre for Assistive Technology and Connected Healthcare (CATCH), School of Health and Related Research, The University of Sheffield, Sheffield, UK

Correspondence to Dr Carolin Elizabeth George; carolinelizabethj@gmail.com

\section{ABSTRACT}

Objectives To describe the initial dilemmas, mental stress, adaptive measures implemented and how the healthcare team collectively coped while providing healthcare services in a large slum in India, during the COVID-19 pandemic.

Setting Community Health Division, Bangalore Baptist Hospital, Bangalore.

Study design We used mixed methods research with a quantitative (QUAN) paradigm nested in the primary qualitative (QUAL) design. QUAL methods included ethnography research methods, in-depth interviews and focus group discussions.

Participants A healthcare team of doctors, nurses, paramedical and support staff. Out of 87 staff, 42 participated in the QUAL methods and 64 participated in the QUAN survey.

Results Being cognizant of the extreme vulnerability of the slums, the health team struggled with conflicting thoughts of self-preservation and their moral obligation to the marginalised section of society. Majority $(75 \%)$ of the staff experienced fear at some point in time. Distracting themselves with hobbies (20.3\%) and spending more time with family $(39.1 \%)$ were cited as a means of emotional regulation by the participants in the QUAN survey. In the QUAL interviews, fear of death, the guilt of disease transmission to their loved ones, anxiety about probable violence and stigma in the slums and exhaustion emerged as the major themes causing stress among healthcare professionals. With positive cognitive reappraisal, the health team collectively designed and implemented adaptive interventions to ensure continuity of care. They dealt with the new demands by positive reframing, peer support, distancing, information seeking, response efficacy, self-efficacy, existential goal pursuit, value adherence and religious coping.

Conclusion The novel threat of the COVID-19 pandemic threw insurmountable challenges potentiating disastrous consequences; slums becoming a threat to themselves, threat to the health providers and a threat for all. Perhaps, a lesson we could learn from this pandemic is to incorporate 'slum health' within universal healthcare.

\section{Strengths and limitations of this study}

- To the best of our knowledge, this is the first article exploring the experiences of a healthcare team working in a large slum in India during the COVID-19 pandemic.

- It offers valuable insights into complexity, vulnerability and lessons of resilience from real-life settings that could help build evidence regarding slums and their health providers who are often missing from the existing scientific literature.

- The researchers being a part of the slum healthcare ecosystem are in a strong position to understand and interpret the context. However, the possibility of personal bias and power bias cannot be ruled out.

- Purposive selection of participants and its potential for judgement bias, use of practical objective questionnaire instead of a previously validated instrument and not exploring personality traits that play a role in stress, coping and resilience are the limitations of the study.

\section{BACKGROUND}

The COVID-19 is an unprecedented pandemic that has led to millions being affected and thousands dying everyday across the world. India reported its first case in the state of Kerala on 30 January 2020. ${ }^{1}$ In a matter of few months, India has crossed the mark of 145380 -confirmed COVID-19 cases as on 26 May $2020 .^{1}$ More than a billion inhabitants, pronounced inequity, and poor healthcare networks pose a significant challenge to fighting this pandemic in this country. Within that fight, urban slums, home to 65.49 million people in India are the most challenging environments. ${ }^{2}$ Overcrowding, low-rise, illventilated shanty buildings, narrow insanitary filthy lanes, social fragmentation and exclusion are the hallmarks of slums. ${ }^{3}$ These factors, along with poor food security, indoor 
air pollution, the impossibility of social distancing and limited health infrastructure, make slums vulnerable to the COVID-19 infection and higher mortality. ${ }^{45}$

As a result of the factors discussed above, slum communities are extremely vulnerable to the current pandemic, not only from the perspective of direct health risks but also from the perspective of its long-term consequences. While the need for access to good and affordable healthcare is obvious, it is exceptionally challenging to provide such care in this setting. This challenge is further complicated by stigma and social prejudice. The Indian media, sensationalised recent news about the COVID-19 outbreak in the Dharavi slum of Mumbai, portraying slum dwellers as disease spreaders who threatened the health and security of other citizens. ${ }^{67}$ This has led to non-compliance with government rules and violence to COVID-19 mitigation efforts in many slums. But in the later stage of this pandemic, the efforts of the Mumbai health authorities to manage COVID-19 in Dharavi slums were applauded by the chief of the WHO as a global role model for effectively managing the spread of novel coronavirus in slums. ${ }^{8}$

In the context of heightened 'COVID-19 anxiety' and stigmatisation, slums require supportive and responsive healthcare systems to stand up to the mounting challenges. While most of the urban primary health centres (U-PHCs) are yet to be established in the state, the existing urban health centres were forced to get involved in pandemic-related activities with a reduced focus on routine healthcare services such as non-communicable disease (NCD) management and Reproductive and Child Health (RCH) services. Similarly, while the tertiary care systems were preparing themselves for this pandemic, most of the private primary care clinics in the slums have closed down. ${ }^{9}$

There are many reasons for the same. Constrained infrastructure, limited human resources, non-availability of personal protective equipment (PPE), cost escalation of care, exhaustive disinfection demands, environmental vulnerability and pre-existing social prejudices pose a significant challenge in running the primary care clinics in a low resource setting.

Being plagued by poverty and extreme health vulnerability, people in slum areas also inordinately suffer from the killer diseases, including waterborne diseases, tuberculosis and NCD like diabetes and hypertension in addition to COVID-19. ${ }^{10}$

Primary care services thereby play a crucial role in managing existing diseases while simultaneously crafting a coherent response to the novel COVID-19 pandemic. Its role in preventing disease complications (myocardial infarction, stroke, renal failure etc), providing emergency care, offering preventive services such as antenatal care and immunisationwhile formulating a multifaceted response (to educate, identify, treat and refer) to this pandemic is indispensable. ${ }^{11} 12$

Realising the exponential growth of unorganised slums in the cities, their increased health demands and the absence of any existing comprehensive health programme, National Urban Health Mission (NUHM) was launched in 2013. It envisages meeting the healthcare needs of the urban poor by proposing U-PHCs for every 50000 population within or 500 metres of the slum. NUHM is set to cover the country's seven big metropolitan areas and 772 cities with a population of more than 50000 people with an investment of INR225 billion into the healthcare sector in a phased manner. ${ }^{13}$ Though some initiatives were rolled out as a part of NUHM, the coverage of the government health system in many of the slums in India is far from ideal.

The Bangalore Baptist Hospital (BBH) has rendered primary care services in slums of Bangalore through its standalone community and mobile clinics for more than a decade. Though cognizant about the health demand in the slums, we did debate over 'self-preservation' versus 'moral contract' to the society during the pandemic. The objective of this paper is to describe the initial dilemmas and consideration, mental stress, adaptive measures implemented and way in which the team collectively coped with the situation. This paper describes the experience of running healthcare services in one of the biggest slums of Bangalore during the first 40 days of the COVID-19 pandemic. These experiences may help us improve the healthcare services in slums and to better prepare for future epidemics and pandemics.

\section{METHODOLOGY \\ Setting}

The hospital

$\mathrm{BBH}$ is a tertiary care hospital that was started in the early seventies as a not-for-profit organisation built on Christian values. $\mathrm{BBH}$ exists to serve the needy irrespective of their religion, caste and socioeconomic status and also has a mixed pool of employees across different faith. The Community Health Division extends its services to 1083 villages of Bangalore Rural District (one million population) and twelve slums within Bangalore city (additional one million people).

\section{The slum}

The United Nations operationally defines a slum as 'one or a group of individuals living under the same roof in an urban area, lacking in one or more of the following five amenities': (1) durable housing (a permanent structure protecting from extreme climatic conditions), (2) sufficient living area (no more than three people sharing a room), (3) access to improved water (water that is sufficient, affordable and can be obtained without extreme effort), (4) access to improved sanitation facilities (a private toilet or a public one shared with a reasonable number of people) and (5) secure tenure (de facto or de jure secure tenure status and protection against forced eviction). ${ }^{14}$

Devarajeevanahalli (DJ Halli) is one of the largest government notified slums in Bangalore, extending over $1 \cdot 15 \mathrm{~km}$ with 50000 population. ${ }^{1516}$ A study by the primary 


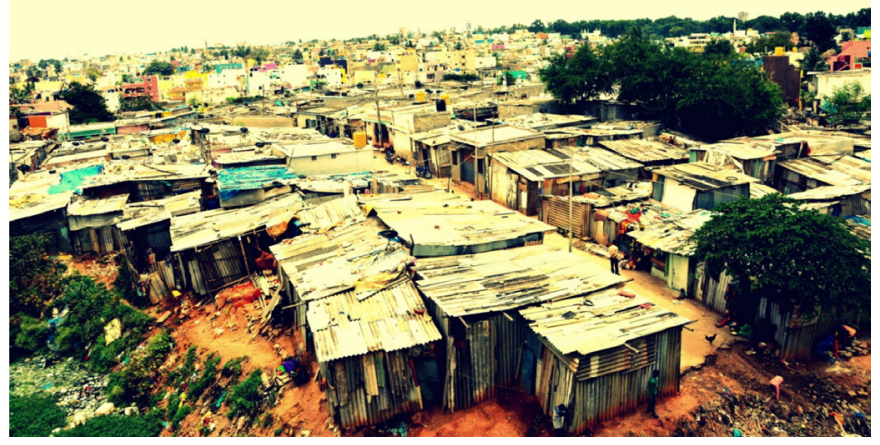

Figure 1 Aerial view of Deveraljeevanahalli (DJ Halli) Slum, Bangalore, India.

author of this article reported poverty $(70.4 \%$ belonged to below poverty line), inadequate physical living conditions (68\% lived in structures that had only one room), poor penetration of medical insurance $(4.1 \%)$ and income insecurity (figure 1) ${ }^{16}$ Only one-third had a regular job (at least 3 days in a week) with an average daily income of INR 304.2 (US\$4.3) and most worked in the unorganised sector. $^{1617}$

\section{Study design}

We used mixed methods research with a quantitative (QUAN) paradigm nested in the primary qualitative (QUAL) design. ${ }^{18}$ This design helped the researchers explore diverse perspectives and uncover complex relationships in this unique social and cultural context. The research was underpinned by an interpretivist approach, which recognises the subjective nature of knowledge, the need to understand situations from the perspective of those involved and the shared meaning-making between the researcher and the participants. ${ }^{19} 20$

\section{QUAL}

We conducted an ethnographic study, where ethnography was applied to understand and describe a distinct experience of continuing health services in slum settings. The researchers CEG (PhD student, MBBS, MD, woman) and LRI (MBBS, MD, man) were trained and experienced in QUAL research methods. The researchers were part of the health team, and all participants were colleagues of the interviewers. In ethnography, the focus is on 'understanding how people live their lives in their sociocultural worlds', ${ }^{21}$ and the goal is to provide an interpretive-explanatory narrative and meaning of people's behaviour including their beliefs and expectations, which are sociocultural in nature. ${ }^{22-24}$ Culture in general is defined as 'shared patterns of learnt values, beliefs and experiences of a group that provide a sense of identity and guide individuals, often unconsciously, in their thoughts, actions and decision-making $\cdot{ }^{25}$ However, in this study, we employed microethnography, in which culture is defined more narrowly as a subculture of healthcare professionals delivering care in slum settings during COVID-19 outbreak. ${ }^{26} 27$

We took a descriptive, exploratory approach and employed the QUAL research techniques of participant observation, ethnographic interviewing and focus group discussions (FGDs). ${ }^{22} 28$ Participants were purposively selected based on their experience and their ability to express. During participant observation, the researcher's intention was known to the group being studied. The researchers played a dual role in observing and participating, yet the emphasis for the researchers was to collect data, rather than participating in the activity being observed. With a deep understanding of the research question, the researchers moved from descriptive observation (observes anything and everything) to focused observation (the participant's interaction insights guide what to observe) and finally to selective observation (directed by researchers insights gained over the previous observations) ${ }^{29}$ Ethnographic interviewing is an informal one-on-one interview taking place in a naturalistic setting, following the participant observation. ${ }^{22} 30$ To enhance understanding and gain deeper insights, we conducted FGD, which allowed social interaction between participants using an interview guide. Researchers with methodological expertise and contextual knowledge developed the interview guide and pilot tested with two participants. The interview and FGD guide predominantly consisted of open-ended questions that probed the significance of the pandemic (how it affected them personally), perceptions about their susceptibility to infection (threat susceptibility) and the severity of COVID-19, their mental stress and how they were managing them (coping methods). The duration of the in-depth interviews and FGDs ranged from 30 to $45 \mathrm{~min}$ and 45 to $60 \mathrm{~min}$, respectively. Ethnographic interviews and FGDs were audio-recorded (after having taken an oral permission), transcribed and analysed along with field notes. Fieldnotes with narrations of what was observed, including informal conversations, meeting notes and other documents available in the setting, were considered in the analysis to enhance the understanding of the context. The essence of the findings was discussed with the participants at multiple instances to maximise the efficiency of the field experience and minimise researcher bias, in order to make the findings as objective and truthful as possible.

\section{QUAN}

We conducted an anonymous survey using a semistructured questionnaire (designed based on the themes that emerged from FGDs and in-depth interviews) through virtual Google form to assess the mental stress and coping strategies objectively (online supplemental file 1).

The questionnaire had three sections (demography, mental health and coping strategies) with 21 questions:

a. The demography section contained six questions regarding age, gender, type of occupation etc.

b. The section on mental health contained seven questions asking about participants' stress, fear, anxiety 
and worry on a Likert scaler in the last 40 days and five questions related to participants' mood and emotions.

c. The final three open questions were on coping strategies. We used the theoretical model of stress and coping process by Folkman and Greer and Health systems Resilience framework to assess the fitness of these models in our context. ${ }^{31}$

\section{Data analysis}

All the QUAL data were collated and analysed using the framework approach. ${ }^{15} 17$ The complexity of the real-life health system in a pandemic and analysis of multiple perspectives from a variety of data sources were the reasons to choose framework analysis. Using the framework method, we followed a combined flexible approach to analysis, enabling themes to develop inductively from interviews (experiences and views) and deductively from the existing literature (coping theories). The interviews and FGDs were transcribed and read through multiple times to familiarise the data and then open coded. Two researchers read a couple of interviews in each category losely, identified key themes and patterns, reviewed the data multiple times and developed codes manually in the initial stage. After researchers open coded the initial transcripts independently, we agreed on a set of codes, each with a brief definition, which formed the initial analytical framework. The researchers then independently coded all the transcripts using the initial framework, taking care to note any new codes or impressions that did not fit the existing set. The process of refining, applying and refining the analytical framework was repeated until no new codes were generated. The final framework consisted of 33 codes, clustered into 10 subcategories and 3 broad categories, each with a brief explanatory description of their meaning and examples of what ideas or elements might be summarised under that code. In the next stage, we applied the final analytical framework to each transcript manually. Once all the data had been coded using the analytical framework, we summarised the data in a matrix for each theme using Microsoft Excel. In the final interpretation stage, we reviewed the matrix and made connections within and between participant and categories. And finally, we tried to go beyond descriptions of individual cases towards developing themes that were meaningful in context and offered possible explanations for research questions.

QUAN data were analysed using SPSS V.20.0 and reported as frequencies, percentages means and SD. We merged QUAN and QUAL results to compare, contrast and synthesise the results. The results, thus generated, were mapped into the theoretical model of stress and coping process to see the fitness of the model. ${ }^{32}$

\section{Data credibility}

The participants read through the transcripts to comment on the accuracy of the texts and corrected them if required. The researchers belonged to the healthcare team and were familiar with the cultural context of other participants and the setting. This improved the validity of the interpretations of the data.

\section{Role of funding source}

We did not receive funding for this study and the corresponding author had full access to all the data in the study and had final responsibility for the decision to submit for publication

\section{Patient and public involvement}

This research was done without patient involvement. Patients were not invited to comment on the study design and were not consulted to develop patient-relevant outcomes or interpret the results. Patients were not invited to contribute to the writing or editing of this document for readability or accuracy.

However, the participants of the study were involved in developing the study tool, reading the final manuscript.

\section{RESULTS}

QUAN

Among 87 team members, 64 completed the survey with a response rate of $73.5 \%$. The mean age group was 34.6 (SD 10.7), and most of them belonged to 20-30 years. The majority of the participants had 1-5 years of experience with a mean of 7.4 years (table 1 ). In the survey, a vast majority $(68.8 \%)$ reported no fear of coming to work during the survey period.

Happiness was the predominant feeling in the last 40 days among $36 \%$ of the team members. Majority $(75 \%)$ of them reported that they experienced fear at some point of time. (figure 2). Distracting themselves with hobbies $(20.3 \%)$ and spending more time with family $(39.1 \%)$ were cited as a means of emotional regulation by the participants. A significant proportion of them (40.6\%) reported prayer as the most critical thing that they do to overcome the unpleasant experiences related to COVID-19.

\section{QUAL}

We conducted four FGDs (two clinical groups, one field group and one support group) and 10 in-depth interviews. The results are organised into three sections: (1) stress of the healthcare team, (2) adaptive interventions and (3) coping strategies.

\section{Experience of the healthcare team}

Stress related to corona pandemic

Stress can be expected when individuals perceive high susceptibility to a potentially lethal infection. The team appraised themselves as 'highly susceptible' in terms of contracting the virus. 'Slums are dense, no way of physical distancing... the chances of getting this infection is high if we continue our services there'. They also reported contracting infection is of 'high personal significance' as it involves stigma, isolation and death. Most people will be okay... 80\% don't even know they had an infection. Sometimes it is good to get it... but what if I am in the 
Table 1 Sociodemographic characters of the participants

A. Sociodemographic characters of the participants in the qualitative study

\begin{tabular}{llll}
\hline Variables & Category & Number & Percentage \\
\hline Gender & Female & 40 & 62.5 \\
& Male & 24 & 37.5 \\
& $20-30$ & 28 & 43.8 \\
& $31-40$ & 20 & 31.3 \\
& $41-50$ & 11 & 17.2 \\
& $51-60$ & 2 & 3.1 \\
Occupation & Doctors & 20 & 4.7 \\
& Nurses & 14 & 31.3 \\
& Field staff & 14 & 21.9 \\
& Allied health & 10 & 21.9 \\
& professionals & & 15.6 \\
Years of & Others & 6 & 9.3 \\
experience & 1-5 & 34 & 53.1 \\
& 6-10 & 16 & 25.0 \\
& $11-15$ & 5 & 7.8 \\
& $16-20$ & 4 & 6.3 \\
Chronic & No & 5 & 7.8 \\
illnesses & Yes & 12 & 81.3 \\
& No & 5.8 & \\
\hline
\end{tabular}

B. Sociodemographic characters of the participants in the qualitative study

\begin{tabular}{|c|c|c|c|}
\hline $\begin{array}{l}\text { Focus group } \\
\text { discussion } \\
\text { (FGD) }\end{array}$ & Group & $\begin{array}{l}\text { Age (in years) } \\
\text { range }\end{array}$ & Gender \\
\hline FGD-1 & Doctors (6) & $34-56$ & $4 \mathrm{M}, 6 \mathrm{~F}$ \\
\hline \multirow[t]{2}{*}{ FGD-2 } & Nurses (5) & $20-33$ & $1 \mathrm{M}, 4 \mathrm{~F}$ \\
\hline & $\begin{array}{l}\text { Allied health } \\
\text { professionals (4) }\end{array}$ & 20-33 & $2 \mathrm{M}, 2 \mathrm{~F}$ \\
\hline \multirow[t]{3}{*}{ FGD-3 } & Field staff & & \\
\hline & $\begin{array}{l}\text { Community } \\
\text { health workers } \\
\text { (9) }\end{array}$ & $28-44$ & $9 \mathrm{M}, 0 \mathrm{~F}$ \\
\hline & $\begin{array}{l}\text { Social workers } \\
\text { (2) }\end{array}$ & $36-42$ & 2M.OF \\
\hline \multirow[t]{2}{*}{ FGD-4 } & Drivers (6) & $34-46$ & $6 \mathrm{M}, 0 \mathrm{~F}$ \\
\hline & $\begin{array}{l}\text { Housekeeping } \\
\text { staff (2) }\end{array}$ & $31-44$ & 0M,2F31 \\
\hline \multirow[t]{6}{*}{$\begin{array}{l}\text { In-depth } \\
\text { interviews }\end{array}$} & Doctors (4) & $34,43,55,35$ & $\begin{array}{l}2 \mathrm{M}, 2 \mathrm{~F} \text { (all } \\
\text { married) }\end{array}$ \\
\hline & Nurses (2) & 26,28 & $\begin{array}{l}\text { OM,2F (all } \\
\text { unmarried }\end{array}$ \\
\hline & Nurse aid (1) & 32 & $\mathrm{~F}$ (married) \\
\hline & $\begin{array}{l}\text { Lab technician } \\
\text { (1) }\end{array}$ & 64 & M (widower) \\
\hline & Driver (1) & 35 & $\mathrm{M}$ (married) \\
\hline & $\begin{array}{l}\text { Field counsellor } \\
\text { (1) }\end{array}$ & 23 & $\mathrm{~F}$ (unmarried) \\
\hline
\end{tabular}

$20 \%$, scary, hmm.' (doctor's interview). Risk perception (product of perceived severity and perceived susceptibility) of the health team was high as they rated high perceived susceptibility and severity to COVID- 19 infection. ${ }^{33}$ Our analysis revealed that health professionals experienced emotions of fear, anxiety and stigma during the pandemic.

\section{Fear}

\section{Fear of contracting the infection}

Fear of infection was the primary concern for all the health team members. Severe infection and death were discussion points at all homes. "What will happen to my children if I die? They are so small...who will look after them?' a doctor aired her concern. Health vulnerability of the slum, nature of the disease and news reports escalated their woes and worries 'People live so close to each other... slum is a high-risk area, you know. In the initial phase, there won't be any symptoms'. 'Infact, yesterday I thought of myself on a ventilator'. Reluctant disclosure of high-risk history by patients eroded trust and sometimes led to patient phobias. 'Yesterday, I saw a patient and towards the end of the consultation, she told about her travel to Mecca a week back. I am worried that I may get Corona'.

\section{Fear of violence in slums}

A mandatory lockdown imposed by the government to curb the spread of COVID- 19 created an existential anxiety in the slums. Despite strict law enforcement, slum dwellers indulged in minimal economic activity leading to clashes and violence, which the healthcare workers were worried they would become victims of 'Yesterday police beat people for opening the shops...they ran through the clinic. What all will happen, nobody can predict. We are stuck in the middle of all... can be dangerous'. Another concern was the resistance of the population to the changes like wearing masks, entering the clinic one by one and following cough etiquettes 'People do not have wages, and they are very stressed. We are cautious in the clinic, patients come without masks, but it is difficult to enforce, they turn violent sometimes...'.

\section{Guilt}

Another primary concern was the thought of passing the infection to family members, especially the elderly and children. While healthcare workers often accept increased risk of the disease as a part of their chosen profession, they exhibited concern about family transmission, especially the elderly, immune compromised or those who have chronic medical conditions. I may give the infection to mother in law or my 8 year old... if something happens to them, how will I forgive myself? Isn't it terrible?' 'They dread the possibility of passing the infection to the vulnerable in their homes'.

\section{Stigma}

To aid the containment of infection, government officials traced the infective person to their homes and ink their 


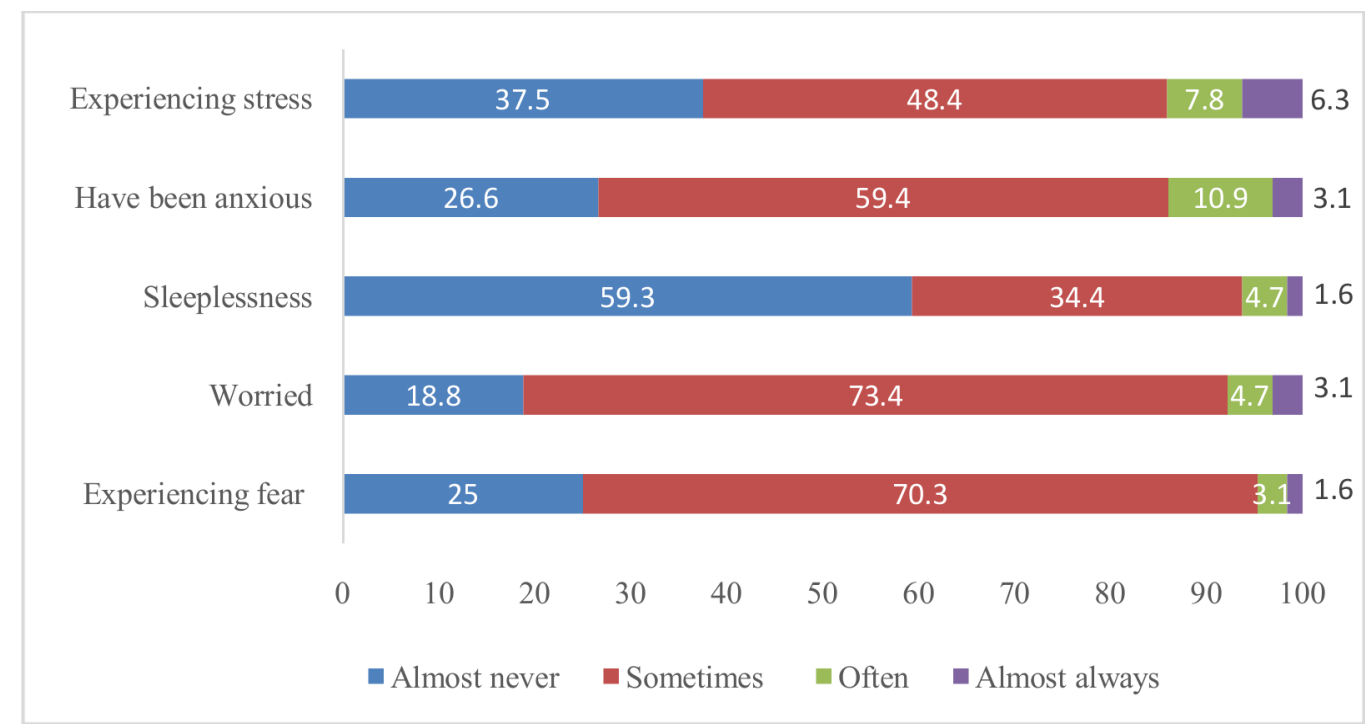

Figure 2 Mental health (negative emotions) of the participants

palms. 'Getting a seal...it is terrible. The whole locality will tell us to get out from where we live'. There is social monitoring of the 'infected and their family members'. Based on the number of cases, an area is classified into different coloured zones, and in red zone, there is a substantialrestriction of movement, transport and commercial activity. This has led to a widespread stigmatisation.'The other day, my house owner called and asked, 'Why can't you resign your job as a nurse? It is putting your family and our whole neighbourhood into risk". The people in the locality saw health workers as carriers of infection and avoided them as a measure of self-protection.

\section{Exhaustion and burn out}

The emotional toll of working in dangerous conditions filled with uncertainties drained health professionals. Attending to patients fully clad in PPEs also exhausted them physically. We are drenched in sweat, we take turns, it is difficult to see patients more than 4 hours at a stretch wearing this' Ever since I started wearing masks at work, I wake up at odd hours...hmm I feel sleep deprived and tired during the day...not sure why?...' They also had intense household demands due to lockdown. After reaching home from the clinic, I have to wash my clinic clothes, take bath, cook and do all household chores. No maid because of lockdown, it is so tiring'.

\section{Stress associated with the change in societal norms}

Chatting with neighbours, social gatherings, visiting the sick, festivals, and social functions were everyday affairs in Indian culture. Physical distancing, rule of 'no-touch or hugs,'absence of social functions and gatherings have created enormous stress on the individual, communities and society as a whole.

'No prayer meetings, no visitors. When will all this end?'.

'I can't even kiss my child so stressful'.
'My marriage scheduled in May is postponed now... when will I get married?'.

These were the voices of healthcare staff who shared their concerns due to new norms.

\section{Adaptive interventions}

De-centralised, participatory and practical measures were instituted to improve the safety.

\section{Realignment of slum health service}

The existing infrastructure was reallocated into waiting and designated hand wash area. The consultation rooms were shifted to open space to ensure adequate ventilation. Segregated patient flow was instituted using visual triage for the screening of middle east respiratory syndrome and isolated fever clinic. ${ }^{34}$ Remote consultation opportunities like teleconsultation, medicine drop-off at homes or proxy medicine pick-ups and prescribing chronic medications for a longer duration were encouraged. The universal use of barrier precautions (masks, gloves, gowns and eyewear) was implemented considering the threat of undiagnosed but infected patients. Reusable waterresistant PPE was designed and rolled out, anticipating the shortage of supplies and the cost escalation. Another critical aspect was the inclusiveness of the 'healthcare' and the 'support team (drivers, housekeeping and laundry) in the preparedness plan. All were trained in handling patients if needed and given full PPE in the initial phase. Two times per day disinfection using $70 \%$ ethanol or $1 \%$ sodium hypochlorite of all common areas and frequently touched surfaces was ensured (table 2).

\section{Transparent communication}

One of the first initiatives was to establish a communication routine to foster collective action rooted in trust. This gave an avenue to openly and proactively share relevant and reliable information to all in a timely and 
Table 2 Adaptive interventions

\begin{tabular}{lll}
\hline Category & Barriers & Interventions adopted \\
\hline Infrastructure & III-ventilated consultation & Open space consultations \\
rooms & A designated waiting area and hand wash area \\
Health worker safety & Increased chance of infection & Psychosocial readiness and support \\
measures & Fear of contracting the & Open discussions \\
& infection & Access to counselling services \\
& & Personal protective equipment (PPE) \\
& Reusable water-resistant PPE \\
& Support staff inclusion \\
& Hydroxychloroquine chemoprophylaxis \\
& Guidelines for screening, quarantine and isolation
\end{tabular}

\begin{tabular}{|c|c|c|}
\hline \multirow[t]{2}{*}{ Patient care } & \multirow[t]{2}{*}{$\begin{array}{l}\text { Overcrowded OPDs } \\
\text { III-ventilated rooms }\end{array}$} & $\begin{array}{l}\text { Segregated patient flow } \\
\text { Triage using visual triage scale } \\
\text { Separate fever clinic }\end{array}$ \\
\hline & & $\begin{array}{l}\text { Strategies in place to minimise routine out-patient visits } \\
\text { teleconsultation and medicine drop-off at homes proxy } \\
\text { medicine pick-ups by younger family members chronic } \\
\text { medications for a longer duration }\end{array}$ \\
\hline $\begin{array}{l}\text { Bio medical waste } \\
\text { management and } \\
\text { disinfection }\end{array}$ & - Increased chance of infection & $\begin{array}{l}\text { Routine disinfection: } \\
\text { Twice a day disinfection using } 70 \% \text { ethanol or } 1 \% \text { sodium } \\
\text { hydro chlorite }\end{array}$ \\
\hline Evaluation & $\begin{array}{l}- \text { Changing realities } \\
- \text { Changing Guidelines }\end{array}$ & $\begin{array}{l}\text { - Review meetings } \\
\text { Open discussions } \\
\text { - Auditing } \\
\text { - Review of policies }\end{array}$ \\
\hline
\end{tabular}

OPD, Out Patient Department.

digestible manner. Knowledge was shared from credible sources, empowered people to look into reliable sources for updates, discussed the 'hype and misinformation' in media and the impact of COVID-19 on the world, nation, state, on the institution and themselves. Empathetic discussions acknowledging vulnerabilities and accepting uncertainties were a hallmark of these discussions. Since the team was diverse (public health experts, doctors, nurses, paramedics, social workers, counsellors, community health workers and drivers), these active dialogues fostered solidarity through collaborative learning and peer support. Periodic communications with faith-based values were also an integral part of COVID-19 response initiatives.

\section{Coping strategies}

Healthcare professionals used multiple coping strategies to tide over the threat associated with COVID-19 (table 3). They used emotion-focused coping with regulating their emotions by being aware of their negative mental representation, avoidance of negative rumination, cognitive reappraisal and positive reframing. Healthcare professionals used problem-focused coping with initiating actions reducing the risk of infection. Though these coping strategies resulted in positive emotions, they sometimes struggled with the non-resolvable facet ( whatever we do, we have increased chance of this deadly infection') of the pandemic. They used meaning-focused coping with deriving meaning from the stressful experience to sustain well-being despite difficult times (figure 3).

\section{Emotion-focused coping}

Healthcare professionals reported maladaptive coping like denial (Indians have immunity'), wishful thinking ('medicine will come soon'), escape avoidance ( I do not want to hear about corona') and fatalism( 'we can't 
Table 3 Coping strategies of the healthcare team

Open codes illustrative quotes

Avoidance:

'When I reach home from hospital, we sit together and talk...now we have more time...children have no school... earlier we sit and watch TV together...now we decided not to do that... Every one in TV is talking about corona... how many died? How many are getting it...how they go from one hospital to hospital and then how they die... my friends also send many horrible things in messages... how corona can go inside heart, head and all... I am coming to hospital ...so I show all this to doctors and nurses... they say that many things are not like this. So I stopped seeing about corona in my phone...All TV is hype. we do not see it at home. if we believe what is coming in whatsapp and TV, then we feel we are going to die now...'(Driver, FGD)

'Many things are unknown. No one has an answer, science and medicine are gathering evidence and knowledge... The only assuaring thing is that we are not seeing people dying right, left and centre... But the media seems to know everything, especially the negative side...So I look at news only once a day... if I see Corona, I just skip the message, as far as I know media is not the most authentic source for COVID(Doctor, Interview)

\section{Gathering credible information}

Everybody is worried, especially because we work in hospital. At home, my wife, children, parents, all are so worried... and you know neighbours also asks my wife...isn't dangerous to work in hospital? Thousands of people in many countries died and now it is in India also. And in the hospital, all these pateints will reach...it can be very risky,you know... I tell my wife and kids what we talk in the hospital...that is the truth... We talk and discuss things, our doctors explains what is the risk, what is that we should do to protect ourselves... and also how important is our role now. The doctors and nurses are seeing patients and touching...so they are also at risk. But they know how to protect. That's why I tell them to trust what our doctors say...(Driver, FGD)

I ask the doctors, that helps me...(House keepingstaff, FGD)

\section{Social connection}

'I am thankful that I can come and see people, talk to people because I am working in a hospital...can't think of sitting at home40 days. My brother was working in a company...they called him and told that no need to come.it was shut for some time, now it is opened, but my brother is not called back... He gets irritated sitting at home all the time...can't go out and meet frineds also.when I reach home in he evening, all look so stressed.I atleast see my friends, able to help people....'(Nurse,FGD)

\section{Earning opportunity}

'In all my family and among 6 siblings, I am the only one who got salary...thankful for the job in hospital'(Driver, Interview)

\section{Gratitude}

'Blessed to be alive and have food to eat. There is more chance of infection and death and all in hospital, but whatever it is, I have a salary...I am able to feed my family.l am grateful for my job at hospital.all other jobs are unsure.' (Lab tech, Interview)

Access to care

'This is the time all are scared of dying... what wil happen if we get corona, where will we go to get treatment? How much will be the money... who will pay? what if we need ICU, we do not have money to pay lakhs... we all pray that we do not get sick. all are scared, my family, my friends, relatives, neighbours.It is scary, but My hospital will look after me even if I get corona... I feel blessed to work in a hospital'(Nurse aid, Interview)

\section{Bonding}

We have each other to talk to... we pray and eat together...I miss all if I don't come for work...the hospital is a part of my life...(Nurse FGD)

Emotional sharing

It is a time of high stress. when I reach home, I think whether I am carrying infection home, will $i$ infect my family? What happens to my children ... all fears are real now... we only know after sometime, the after effect of our decisions... but when we reach the hospital, the burden lightens... we have collegues whom we can share our burdens... We share our fears, worries about children...sometimes I breakdown... after that I come out strong... allows me to laugh again...(Doctor interview)
Organising theme

Distancing

Global theme

Emotion-focused coping 
Table 3 Continued

\section{Open codes illustrative quotes}

\section{Adequacy of PPEs}

'We are protected. I am happy all of us have PPEs...it protects us and our families'(Doctor FGD)

'Every day, mychildreminds me-papa do not forget to wear your special dress. Corona can't get inside'(Driver, FGD)

\section{Disinfection preparation}

Even in the vehicle we have put a sanitiser and bacilloid spray. We are prepared. (Nurse aid, Interview)

\section{Training}

The training helped us to wear the PPE and become clinic assistant in transferring and transporting sick patients.

(Driver, FGD)

\section{Practice}

Everyday morning there is a drill. I am confident(Driver, Interview)

I am able to do whatever we decided. Changing into full PPE, maintaining distance, decontaminating hands and surfaces. It is practical(Nurse, FGD)

We wear PPE everyday... We do not know who has the disease.All of us together decide what to do, so that all of us are protected... we protect each other. We travel together, so one person's causual attitude can infect all of us. That is why we plan carefully and practice precisely(Doctor, FGD)

I have performed donning and doffing in front of my family. They are happy that I am protected...My daughter looks at me carefully ...I know her anxiety, but after I wear all the gown and face shield, she smiles... she feels that I am ready to fight the virus...(Community Health worker, FGD)

\section{Barrier to patient care}

Sometimes all these added layers makes patient care quite impersonal...smile, touch are very important...they are poor, they are sick...they need to feel that connect for healing... but now we are armoured, anxious, scared... patients gets worried too, you know seeing us in this suit...(Doctor, Interview)

With gowns, face shield and masks we sit 6 metre distance trying to communicate with a patient wearing mask... Most times, it is very difficult to hear them. (Doctor, Interview)

With all gears, we are drenching in sweat. It is tough to carry on for long hours, that's why we take turns. Nurse,Interview

Everyday we have to disinfect the PPEs. The slum clinic is dingy, not much space to do washing and stuff like that... but we cannot carry used PPEs, so we wash them in the clinic, after patients are gone...It is a time consuming and draining activity. (Doctor, Interview)

\section{Vision and mission}

Healing and wholeness in the spirit of Jesus Christ is our vision. Selflessness is a part of it... we are called to serve in the spirit of selflessness... we may get corona, our chances are high...in slums no one wears a mask also... all other clinics are closed except government. We can't leave the people who needs care thinking that we will get COVID... may of the friends in the hospital ask, why are you going to slums... we say it gives me happiness. And that serving poor patients is our mission."(Nurse, FGD)

\section{Commitment to the poor}

Services to the poor is our core...All are suffering but the suffering of poor is unimaginable...all have left them. We have to be there, they need us(Doctor FGD)

We cannot run away from poor thinking that we may get infected... we may get infected, but that is much better than leaving them. We have to do the right thing and the right thing is to care for the poor. (Nurse Interview)

\section{Empathy}

Going and visiting people in slums during this time is dangerous... all are at home, no job, no medicines, no

proper food... there are many people who earn daily wages. what the daily coolie workers will do for their living? I

have to help...l can get them medicines, some food... be a person of help if they need any support...(Community

Health worker, FGD

Poor is suffering ...lot of misery. They do not have any support system...children do not have food to eat... How

can we look at them and decide to walk away? not possible. (Counsellor, Interview)

\section{Altruism}

I could distribute $100 \mathrm{kgs}$ of food to poor. I told my mother, she was so happy. In this time of need, to be able to help others, is something.It makes me happy, useful. My mother worry about me all the time, I tell her what good things $i$ am able to do, how I am able to help others, each day...and then she cannot say to stay at home. (Driver, FGD)

\section{Active religious surrender:}

'There is nothing God cannot change. God decided that I have to do my duties during this time. When the right time comes, He will take the virus away. God is all-powerful,He can change things... we need to keep praying'(Community Health Worker, FGD)

Benevolent religious reappraisal:

'It is all for good... We have slowed down, time for reflection,..pollution also came down, you know God

has a purpose for everything, we may not understand, but I can point out many positive things that is

happening'(Doctor, FGD)

Spiritual connection:

'God cares for us, even in the midst of corona...we are drawn more to God in sufferings ... when things are al good, we often tend to forget God. I personally, my family and my friends all are more prayerful now compared to earlier times...(Nurse, FGD)

Religious helping :

God is using me to be a source of comfort for many...I feel good about it. We are able to reflect many things

together... we are growing together and our relationships have become more meaningful'.(Doctor, FGD)

Religious forgiving:

I am able to tide over my anger and helplessness when I reflect in prayer...it gives me peace even when things are going out of control (Counsellor, Interview)

Organising theme

Global theme

Response efficacy Problem-focused

coping

Self-efficacy

\section{Response costs}

Existential goal

pursuit

Value adherence

\section{Meaning-focused}

coping 


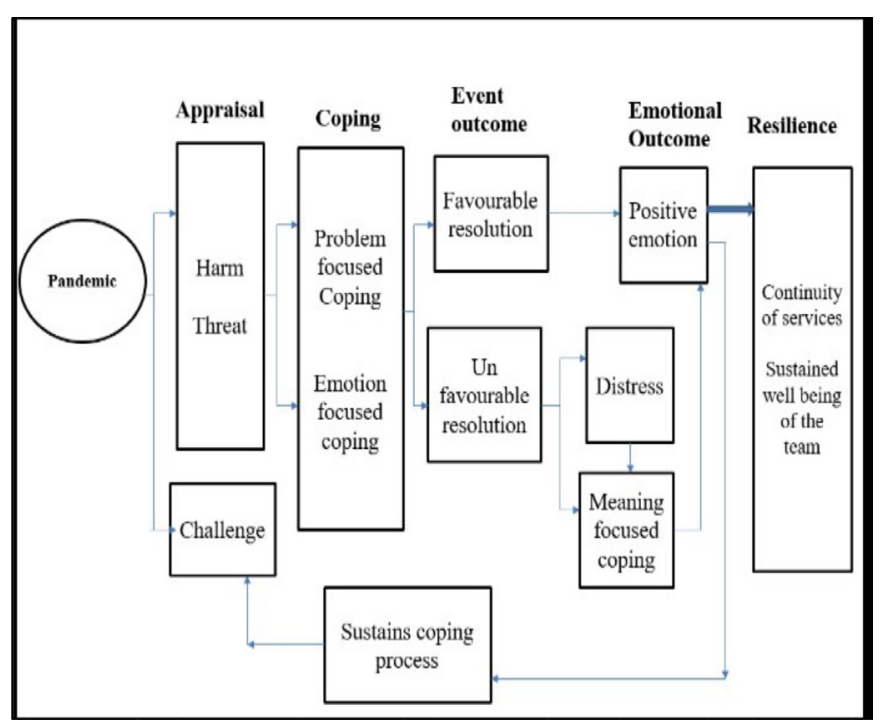

Figure 3 Mapping of study findings on to Folkman and Greer's theoretical model of stress and coping.

do anything') in the initial weeks. Later, they cognitively reappraised the situation in positive ways, reframing the opportunity to work in a hospital as a venue for fostering social connections, earning opportunity and improved access to medical care. They achieved change in their emotional state through information gathering, distancing from media hype and seeking social support.

Health professionals resorted to credible information seeking and practised distancing from media hype to insulate themselves from paralysing fear. I stopped watching the news at home; children get frightened. I tell at home what I hear from the hospital, that is more correct'.

Peer support acted as a source of encouragement and companionship, which brought an array of positive emotions to their life. They prayed and fellowshipped together before starting work. I am happy, I have a good workplace..., we eat and pray together', said one of the nurses. They looked after each other, watched how they were managing patients and reminded each other about infection control. They listened to each other and comforted when needed.

\section{Problem-focused coping}

Being cognizant about the vulnerability of slum, the team chalked out plans to mitigate the risks and implemented it at the earliest. Motivation to be relevant to the poor and determination to sustain the needed services activated their 'problem-solving attributes'. They responded by realignment of slum services, universal use of PPE, effective disinfection methods and other health worker and patient safety measures. High response efficacy (usefulness of the interventions to protect themselves) and selfefficacy (confidence to perform the intervention) were reported for these new initiatives. Though hot weather, difficulty in washing, loss of personal touch in the consultation were pointed out as the response cost (barriers for intervention), the response efficacy outweighed the response costs.
Meaning-focused coping

People used meaning-focused coping like spirituality, goal pursuit and value adherence to deal with non-resolvable facet of the pandemic. Belief in God was reported as the core factor that allowed the healthcare team to cope with their painful experiences. Being founded on the principles of Christian faith, religious beliefs, goals and values were congruent in the institution. Values of compassion, sacrifice, service and reaching out to the poor were held with high esteem at all levels. Healthcare professionals, though belonging to diverse faith imbibed and assimilated these values. Healing and wholeness in the spirit of Jesus Christ is our vision. Selflessness is a part of it... we are called to serve in the spirit of selflessness'-one of the nurses said during the interview.

On a personal level, people used religious coping to find meaning, gain comfort and closeness to God and to achieve a means of life transformation. I seek God's help,' I put my trust in God,' I find comfort and peace in the midst of the pandemic,' 'God has a purpose for everything'-these were their responses during interviews. Many have found a new purpose to their lives, to be a source of comfort to others (religious helping) at this turbulent time.

Periodic communications with faith-based values were an integral part of COVID-19 response initiatives. Nonmandatory activities like morning prayers (giving thanks and words of encouragement) and weekly sessions of spiritual reflection of events were cited by the team members as essential resources in building their resilience.

People also expressed a strong sense of duty to serve poor communities during this crisis. What will coolie workers do?' I have to help poor', 'COVID-19 is very bad for the poor', I distributed rice to the poor'-the list goes on. Values of altruism and empathy towards the poor outweighed negative emotions like fear and anxiety. They considered it as an opportunity to make 'good use' of their lives. 'One day all have to die; the most important thing is to use our lives for doing good, at this time, we are helping others, that is good'. Assigning a purpose to the pandemic helped them to cope with the pandemic situation risking their own lives.

\section{Resource challenges, acceptance challenges and sustenance challenges}

Continuing patient care in a poorly constructed, illventilated clinic in a crowded slum with limited knowledge to evaluate team risk and community risk caused enormous strain on the healthcare team.

Though most of the patient care activities were shifted outdoors, patient registration, laboratory and dental procedures were held in rooms with compromised ventilation. Patient triaging resulted in long queues and prolonged waiting time. Rains disrupted outdoor consultations. Disinfecting PPEs in a space-constrained slum clinic was another herculean challenge. The lockdown further strained the system by a shortage of essential supplies (PPE, medicines). Mounting operating costs 
(eg, earlier on the team used to travel in one vehicle, now two vehicles are used to reduce crowding) and funding crunch (in April and May, all the existing funders wrote to us saying that they are also affected and that they would not be able to commit to providing funds this year) were added to their challenges.

Human resource constraints weighed heavy on the team, when vulnerable (older, pregnant) staff were relived from risky duties. The existing staff juggled their time between designing and operationalising new interventions and providing care. Internalising new norms at a rapid phase, insulating team from response fatigue and sustaining motivation for a longer period are considered as serious challenges.

People in slums reluctantly used the clinic fearingforced eviction if COVID-19 infection was detected. It pushed the health team to define and refine their role and relevance in this community during the pandemic. In short, facility constraints, personnel limitations, operational difficulties, mounting operational costs, funding crunch and community fears created hard hurdles for the health team.

\section{DISCUSSION}

Contextual vulnerability makes the slums a nearly impossible environment for health professionals to function during COVID-19 pandemic. Experiences of providing services to one of the most vulnerable populations in this historical time of crisis can offer valuable lessons from real-life settings. To the best of our knowledge, this is the first article exploring the stress, coping styles and the resilience of a healthcare team in sustaining medical services in one of the biggest slums in India, during this pandemic.

One of the initial findings was the conflict between self-preservation and the moral contract to society. Selfpreservation-the right to life is a fundamental right of every individual. It is one of the essential attributes of medical professionals, necessary to mitigate the risk of their hazardous work environment. In normal circumstances, the healthcare professional can look after the patients without compromising much of their safety. However, in the case of life-threatening pandemics like COVID-19, there is an undue demand on health professionals to provide care to the patients, at times putting their lives at risk. Even with the best protective measures, the risk of potentially lethal infection remains high among healthcare professionals. Though the declaration of Geneva states, 'As a member of the medical profession, I solemnly pledge my life to the service of humanity, the health and well-being of my patient will be my first consideration'-it is difficult or sometimes unethical to demand 'a life sacrifice' from medical professionals on a routine basis. ${ }^{35}$ However, in crisis conditions, these sacrifices become essential to manage and control pandemics. Similar ideological conflicts have been reported in cases of the Ebola and SARS outbreak. ${ }^{36} 37$
Since continuity of services in slums during COVID-19 increases the likelihood of this potentially fatal infection, healthcare workers experienced the fear of death, guilt of transmitting the infection to their loved ones and stigma from community. Frontline healthcare workers had similar experiences during the pandemics. ${ }^{36-40}$ In our study, healthcare professionals reported the stress of new norms, especially that of social distancing. Social scientists from different parts of the world reported that social distancing could suppress evolutionarily hardwired impulses for connection, leading to stress. ${ }^{41}$ The consequences of isolation could be more pronounced in eastern societies due to their collectivistic nature than in western individualistic societies.

Adaptive interventions of the health team were the contextualised practical adaptations of the Centre for Disease Control contingency and crisis strategies preparing for the worst-case scenarios. ${ }^{42} 43$ The ability of the healthcare team to appraise the situation swiftly, leverage collective expertise and deliver practical and costeffective solutions reduced anxiety and promoted a sense of self-efficacy. Ensuring health worker safety as a critical responsibility of a moral institution, the hospital designed reusable water-impervious PPE with the provision of additional disposable layers to ensure safety without huge cost implications. Universalisation of PPE (clinical and support staff) reduced anxiety across all members. Since the support staff may be required to do activities of risk (drivers shifting and transporting suspected patients to another hospital), they were given PPE and trained at the same time as the clinical staff. Pronounced anxiety among support staff and reluctance to come for working in the initial stages vanished after rolling out PPE to them. Ongoing dialogic communication and prompt collective adaptive interventions fuelled continuity of services.

A supportive work environment with a high level of trust and professional cohesion helped health professionals to cope with challenging conditions that were in concordance during the Ebola outbreak. ${ }^{37} \mathrm{~A}$ high level of trust among each other and on the leadership facilitated the rapid implementation of radical collective solutions. Honest communication, empowerment and acknowledging one's own finitude of the situation were identified as critical leadership strategies during a crisis. ${ }^{44}$

An internalised value system like religion was one of the powerful coping mechanisms people used to deal with this pandemic. Religion interprets events and assigns meaning and purpose to these unprecedented shocks. It serves as a powerful medium to gain control, peace and comfort in coping with uncertainties. ${ }^{45}$ Studies reported that people resort to religious coping in pandemics, lifethreatening illnesses and to deal with post-traumatic stress. ${ }^{46-49}$

Health system resilience can be defined as the capacity of health actors, institutions and populations to effectively respond to crises, maintain core functions when a crisis hits and informed by lessons learnt during the crisis, reorganise if conditions require it. ${ }^{50}$ In this study, we have elaborated 
on health workforce resilience, which is an integral part of health system resilience. Resilience dividend (improved performance in both bad times and good) in this system can be attributed to the team's commitment to their mission and values, vigorous public health response to the shock, the strength of social capital, collective learning, the sequential approach of problem-solving and coping strategies and an organisational culture promoting individual and collective resilience. ${ }^{51}$ These qualities were not developed as a response to the crisis but were a part of normal functioning: crisis only amplified the expression and made resilience more visible.

The sheer speed, scale and catastrophic consequences of the COVID-19 in slums are a jolting wake-up call for everyone. For people in slums, the virus containment measures is often a choice between the risk of catching the disease and the certainty of hunger. Hence, their choice of infection and subsequently being super spreaders cannot be condemned. The systemic neglect of the slums has made panic, unrest and massive fatalities a real possibility during the pandemic. It is the responsibility of the government to include slums along with its cities, as they owe much to this informal economy. Slums in Dharavi, India, for example, employ as many as $70 \%$ of its residents with current economic output estimates of US $\$ 700$ million annually. ${ }^{52}$ Other places such as Delhi, Bangalore and Kolkata also depend heavily on the informal sector for supporting their economy. ${ }^{54}$ Hence public health measures mandating integrated slum development have to be accelerated during the post-pandemic period to prevent such future scenarios.

The article brought out a theoretical framework for cognitive appraisal and coping using the theoretical model of stress appraisal and the coping process by Folkman and Greer and discussed the foundations of health workforce resilience, these are highly context driven and have to be generalised cautiously.

\section{Health care provision experiences and learnings}

At the microlevel, pandemic like COVID-19 will challenge any health team's commitment, cohesion and agility and more so in limited resource settings. Even in the midst of crisis, the team can succeed by reflecting on their vision, cultivating a deep mindset of humility, collectivism, accountability and nurturing bottom-up all-inclusive culture. While we were able to sustain the healthcare services in slums during this pandemic with considerable risks to our workforce, had the mortality been greater, we could have lost precious healthcare force, a loss for all and eventually a grave challenge to sustainability.

Given the fact that COVID-19 will not be the last public health threat to the world, the learnings through this crisis should be wake up call for systemic changes in urban governance and city planning. At the macrolevel, the pandemic brings a strong case for improvement of basic amenities in slums, as it strengthens public health and mitigates health threat to the people in slums and cities. Improved public spaces and economic inclusion of slum dwellers in the organised labour sectors would pay colossal health and economic dividends. Linking science to society and promoting community participation with strong health networks is essential to have an effective response in any pandemic. ${ }^{16}$ In short, a resilient health system cannot thrive on its own for a long time, unless cities as a whole become more inclusive and resilient.

\section{CONCLUSION}

The study describes the experience of sustaining essential health services in one of the biggest slums in India during the COVID-19 pandemic. It throws light on the complexities of the context, struggles, adaptability and resilience of a real-life health system in crisis. Fear, guilt, isolation and exhaustion posed considerable stress to the health team in the initial phase. However, with cognitive reappraisal, the health team managed distress using emotionfocused coping, handled the problem causing the distress with problem-focused coping and sustained positive well-being through meaning-focused coping. Organisational culture, shared purpose, adaptability, collaborative learning and meaningful relationships fostered resilience amid crisis. These values were not just crisis specific but were organically built as a part of our system. Hence, this article shows the importance of engraining a culture of resilience as a part of every health system, which then will reap lasting rewards in times of crisis.

This pandemic has taught many valuable lessons. The negation of the reality of slums in cities-and, hence the rights of slums dwellers which in turn allows intolerable living conditions and weak health networks have the potential to wipe out millions in a short span of time. COVID-19 is a wake-up call to include 'slum health' within 'universal healthcare' to insulate the world from fatalities of future pandemics.

Acknowledgements The authors would like to acknowledge Mr Tata Rao for help with referencing. We are grateful for the community health team for the truthful conversations and their cooperation during the study.

Contributors CEG contributed to the conception and design of work, acquisition, analysis and interpretation of data, and was the primary contributor to the draft paper and revisions. CEG and LRI conducted the interviews and performed qualitative analysis. LRI developed the study tool, analysed and interpreted the data, contributed to manuscript writing and critically reviewed the manuscript. SR and LDW contributed to the design of the study, interpretation of qualitative data and critical revision of the paper. All authors revised the work for important intellectual content and agree to be accountable for all aspects of the work. All authors read and approved the final manuscript.

Funding The authors have not declared a specific grant for this research from any funding agency in the public, commercial or not-for-profit sectors.

Competing interests None declared.

Patient consent for publication Not required.

Ethics approval The study was approved by the Ethics Committee of BBH. Informed consent was taken from the participants before FGDS, in-depth interviews and the survey. When we used quotes from meeting notes or discussions, we have obtained permission before using it in the article.

Provenance and peer review Not commissioned; externally peer reviewed.

Data availability statement The datasets used and/or analysed during the current study are available from the corresponding author on reasonable request. 
Supplemental material This content has been supplied by the author(s). It has not been vetted by BMJ Publishing Group Limited (BMJ) and may not have been peer-reviewed. Any opinions or recommendations discussed are solely those of the author(s) and are not endorsed by BMJ. BMJ disclaims all liability and responsibility arising from any reliance placed on the content. Where the content includes any translated material, BMJ does not warrant the accuracy and reliability of the translations (including but not limited to local regulations, clinical guidelines, terminology, drug names and drug dosages), and is not responsible for any error and/or omissions arising from translation and adaptation or otherwise.

Open access This is an open access article distributed in accordance with the Creative Commons Attribution Non Commercial (CC BY-NC 4.0) license, which permits others to distribute, remix, adapt, build upon this work non-commercially, and license their derivative works on different terms, provided the original work is properly cited, appropriate credit is given, any changes made indicated, and the use is non-commercial. See: http://creativecommons.org/licenses/by-nc/4.0/.

\section{ORCID iD}

Leeberk Raja Inbaraj http://orcid.org/0000-0001-8642-1348

\section{REFERENCES}

1 Ministry of health and family welfare COVID-19 India. Available: https://www.mohfw.gov.in [Accessed 25 May 2020].

2 India Office of the Registrar General and Census Commissioner. Primary census Abstract for slum (technical report. New Delhi, India: Office of the Registrar General and Census Commissioner, 2013.

3 Wratten E. Conceptualizing urban poverty. Environ Urban 1995;7:11-38.

4 Thakur M, Boudewijns EA, Babu GR, et al. Biomass use and COVID-19: a novel concern. Environ Res 2020;186:109586.

5 Klein I. Urban development and death: Bombay City, 1870-1914. Mod Asian Stud 1986;20:725-54.

6 With-1-541-Covid-19-cases-Dharavi-adds-to-Mumbai-s-woes. Available: https://www.hindustantimes.com/mumbai-news/with-1541-covid-19-cases-dharavi-adds-to-mumbai-s-woes/story-WX41 109PJzGGaXi2ZxjRAM.html [Accessed Cited 25 May 2020].

7 Concerns after Mumbai's Dharavi slum reports COVID-19 cases. Available: https://www.aljazeera.com/news/2020/04/concernsmumbai-dharavi-slum-reports-covid-19-cases-200403053646046. html [Accessed 25 May 2020].

8 The Hindu. Coronavirus Dharavi a global role model of COVID management, says Thackeray, 2020. Available: https://www. thehindu.com/news/cities/mumbai/coronavirus-dharavi-a-globalrole-model-of-covid-management-says-thackeray/article32051841. ece

9 The New Indian Express. 58 private hospitals shut; $50 \%$ parameds, $30 \%$ of doctors quit in Bengaluru: PHANA, 2020. Available: https://www.newindianexpress.com/states/karnataka/2020/jul/16/ 58-private-hospitals-shut-50-parameds-30-doctors-quit-phana2170322.html

10 Riley LW, Ko Al, Unger A, et al. Slum health: diseases of neglected populations. BMC Int Health Hum Rights 2007;7:2.

11 Kumar S, Kumar S, Gupta B. Urban health: needs urgent attention. Indian J Public Health 2018;62:214-7.

12 Misra A, Pandey RM, Sharma R. Non-Communicable diseases (diabetes, obesity and hyperlipidaemia) in urban slums. Natl Med $J$ India 2002;15:242-4.

13 Bhaumik S. India outlines plans for national urban health mission. Lancet 2012;380:550.

14 Un-Habitat. State of the World's Cities 2006/2007. Nairobi, Kenya, 2006.

15 Karnataka slum development board. Available: https://www. karnataka.gov.in/ksdb/Pages/Home.aspx [Accessed 10 May 2020].

16 George CE, Norman G, Wadugodapitya A, et al. Health issues in a Bangalore slum: findings from a household survey using a mobile screening toolkit in Devarajeevanahalli. BMC Public Health 2019;19:456.

17 XE: Convert INR/USD. India Rupee to United States dollar. Available: https://www.xe.com/currencyconverter/convert/?Amount=304\& From $=$ INR\&To=USD [Accessed 28 Feb 2019].

18 Creswell JW, Clark P, GutmannM, Hanson W. Advanced mixed methods research designs. In: Tashakkori A, Teddlie C, eds. Handbook of mixed methods in social and behavioural research. Thousand Oaks CA: Sage, 2003: 209-40.

19 Braun V, Clarke V. Using thematic analysis in psychology. Qual Res Psychol 2006;3:77-101.

20 Vaismoradi M, Turunen $\mathrm{H}$, Bondas T. Content analysis and thematic analysis: implications for conducting a qualitative descriptive study. Nurs Health Sci 2013;15:398-405.
21 Lawlor MC. Gazing anew: the shift from a clinical gaze to an ethnographic lens. Am J Occup Ther 2003;57:29-39.

22 Spradley J. The ethnographic interview. New York: Holt, Rinehart, \& Winston, 1979.

23 Jegatheesan B. Ways of being in home and community: language socialisationof children with autism in multilingual South Asian immigrant families. Urbana-Champaign: the University of Illinois at Urbana-Champaign, 2005.

24 Watson-Gegeo KA. Ethnography in ESL: defining the essentials. Tesol Quart 1988;22:575-92.

25 Srivastava $\mathrm{RH}$. Culture, religion, and family-centred care. In: Shaul RZ, ed. Paediatric patient and family-centred care: ethical and legal issues. Dordrecht (NL): Springer, 2014: 57-77.

26 Cruz EV, Higginbottom G. The use of focused ethnography in nursing research. Nurse Res 2013;20:36-43.

27 Polit DF, Beck CT. Nursing research: generating and assessing evidence for nursing practice. 8th ed. Philadelphia (PA): Lippincott Williams \& Wilkins, 2008.

28 Sandelowski M. Combining qualitative and quantitative sampling, data collection, and analysis techniques in mixed-method studies. Res Nurs Health 2000;23:246-55.

29 Angrosino MV, Mays de Pérez KA. Rethinking observation: from method to context. Handbook of qualitative research 2000;2:673-702.

30 Jupp V. The SAGE dictionary of social research methods. London: SAGE, 2006.

31 Folkman S, Greer S. Promoting psychological well-being in the face of serious illness: when theory, research and practice inform each other. Psychooncology 2000;9:11-19.

32 Ritchie J, Spencer L, O'Connor W. Carrying out qualitative analysis. In: Ritchie J, Lewis J, eds. Qualitative research practice. A guide for social science students and researchers. Thousand Oaks: Sage Publications, 2003: 219-62.

33 Vlek C, Stallen P-J. Rational and personal aspects of risk. Acta Psychologica 1980;45:273-300.

34 Command and control center Ministry of health Kingdom of Saudi Arabia scientific Advisory board. the middle East respiratory syndrome coronavirus; guidelines for healthcare professional. Available: https://www.moh.gov.sa/CCC/healthp/regulations/ Documents/MERS-CoV\%20Guidelines\%20for\%20Healthcare\% 20Professionals\%20-\%20May\%202018\%20-\%20v5.1\%20\%281\% 29.pdf [Accessed 28 May 2020]

35 Wma Declaration of Geneva. Available: https://www.wma.net/ policies-post/wma-declaration-of-geneva/ [Accessed 10 Jun 2018].

36 Witter S, Wurie H, Chandiwana P, et al. How do health workers experience and cope with shocks? learning from four fragile and conflict-affected health systems in Uganda, Sierra Leone, Zimbabwe and Cambodia. Health Policy Plan 2017;32:iii3-13.

37 Raven J, Wurie H, Witter S. Health workers' experiences of coping with the Ebola epidemic in Sierra Leone's health system: a qualitative study. BMC Health Serv Res 2018;18:251.

38 Liu Q, Luo D, Haase JE, et al. The experiences of health-care providers during the COVID-19 crisis in China: a qualitative study. Lancet Glob Health 2020;8:e790-8.

39 Who calls for healthy, safe and decent working conditions for all health workers, amidst COVID-19 pandemic. Available: https://www. who.int/news-room/detail/28-04-2020-who-calls-for-healthy-safeand-decent-working-conditions-for-all-health-workers-amidst-covid19-pandemic

40 Ayanian JZ. Mental health needs of health care workers providing frontline COVID-19 care. JAMA Health Forum 2020;1:e200397.

41 Holt-Lunstad J, Smith TB, Layton JB. Social relationships and mortality risk: a meta-analytic review. PLoS Med 2010;7:e1000316.

42 Strategies for optimizing the supply of N95 respirators. Available: https://www.cdc.gov/coronavirus/2019-ncov/hcp/respiratorsstrategy/index.html

43 Cavallo JJ, Donoho DA, Forman HP. Hospital capacity and operations in the coronavirus disease 2019 (COVID-19) PandemicPlanning for the Nth patient. JAMA Health Forum 2020;1:e200345.

44 Walton M, Murray E, Christian MD. Mental health care for medical staff and affiliated healthcare workers during the COVID-19 pandemic. Eur Heart J Acute Cardiovasc Care 2020;9:241-7.

45 American Psychological Association. Faith in a time of crisis. Available: https://www.apa.org/topics/covid-19/faith-crisis [Accessed 15 May 2020].

46 Fadilpašić $\mathrm{S}$, Maleč $\mathrm{D}$, Džubur-Kulenović A. Relationship of religiousness and religious coping with quality of life among war trauma survivors. Psychiatr Danub 2017;29:291-301.

47 Adhikari Baral I, K C B. Post traumatic stress disorder and coping strategies among adult survivors of earthquake, Nepal. BMC Psychiatry 2019;19:118. 
48 Tarakeshwar N, Vanderwerker LC, Paulk E, et al. Religious coping is associated with the quality of life of patients with advanced cancer. $J$ Palliat Med 2006;9:646-57.

49 Phelps AC, Maciejewski PK, Nilsson M, et al. Religious coping and use of intensive life-prolonging care near death in patients with advanced cancer. JAMA 2009;301:1140-7.

50 Kruk ME, Myers M, Varpilah ST, et al. What is a resilient health system? lessons from Ebola. Lancet 2015;385:1910-2.

51 Rodin J. The resilience dividend: being strong in a world where things go wrong. New York: Public Affairs, 2014.
52 Gruber D, Kirschner A, Mill S, et al. Living and working in slums of Mumbai. InstitutfürSoziologie, Otto-von-Guericke-Universität Magdeburg. Arbeitsbericht NR. 36. Magdeburg, Germany, 2005. Available: http://www.eurostud.ovgu.de/isoz_media/downloads/ arbeitsberichte/36.pdf [Accessed 28 Apr 2020].

53 Chege PW, Mwisukha A. Benefits of slum tourism in Kibera slum in Nairobi, Kenya. International Journal of Arts and Commerce 2013;2:94-102

54 Benjamin S. Urban land transformation for pro-poor economies. Geoforum 2004;35:177-87. 